\title{
Genetic differences in Alternaria alternata isolates associated with brown spot in tangerine cultivars
}

\author{
Mahsa Rahimi Lengi ${ }^{\mathrm{a}}$, Ali Reza Niazmand ${ }^{\mathrm{a}, *}$, Mohammad Kianoush $^{\mathrm{b}}$ \\ a Department of Plant Pathology, Jahrom Branch, Islamic Azad University, Jahrom, Iran \\ b Fars Research Centre for Agriculture and Natural Resources, Fars, Iran \\ *Corresponding author, e-mail: niazmand@jia.ac.ir, niazmand2003@yahoo.com
}

Received 24 Feb 2014

Accepted 25 Aug 2014

\begin{abstract}
Alternaria alternata is one of the most important fungi causing brown spot on tangerine. Samples of A. alternata were collected from different cultivars of tangerine affected by brown spot in orchards in Jahrom region, Iran. Samples were cultured on potato dextrose agar (PDA) media and purified using the single-spore method. Pathogenicity tests were done based on Koch's postulates on healthy and scratched leaves of different tangerine cultivars. All isolates were pathogenic on both healthy and scratched leaves. Ponkan and Mahalli (local isolates) showed the greatest growth, while Fortune and Kinnow isolates had the least growth on PDA media. The rDNA ITS1 region of Clementine, Mahalli, Ponkan, Lee, Fortune, Kinnow, Page, and Osceola isolates was sequenced. One PCR product (360 bp) was recovered from all mycelia multiplications. Sequences of all isolates were deposited in GenBank. BLAST searches of the NCBI database showed that the closest matches were A. alternata. The morphological tests were supported by molecular experiments. The phylogenetic tree of the sequences was mapped based on neighbour-joining procedures. Grouping of all isolate sequences placed them in two main clusters. Mahalli isolates in cluster 2 were in a different group from the other isolates. In general, the results showed intra-species genetic differences in rDNA ITS1 sequences among A. alternata isolates collected from tangerine cultivars. In this study, A. alternata was identified as the cause of Alternaria brown spot of tangerine cultivars in southern Iran.
\end{abstract}

KEYWORDS: pathogenicity test, ITS1, PCR, phylogenetic tree, sequencing

\section{INTRODUCTION}

Alternaria alternata (Fr.) Keissler, formerly A. citri Ellis \& Pierce, is the main causal agent of Alternaria brown spot (ABS) on tangerine (Citrus reticulata Blanco) and tangerine hybrids in commercial citrus orchards worldwide. ABS was first reported on Emperor mandarin in Australia in $1903^{1}$ and the distribution of the disease has expanded considerably worldwide in recent years. It has been reported in the US ${ }^{2}$, South Africa ${ }^{3}$, Turkey ${ }^{4}$, Spain $^{5}$, Italy ${ }^{6}$, China $^{7}$, Brazil, and Argentina ${ }^{8}$. In Iran, ABS was first described in 2006 on tangerine hybrid cultivars (Minneola, Page, and Fortune) and then on other citrus cultivars $^{9}$.

Alternaria spp. cause several diseases of citrus, including ABS of tangerine, leaf and fruit spot of rough lemon (C. jambhiri Lush.) and Rangpur lime (Citrus $\times$ limonia Osbeck), mancha foliar de los cítricos affecting Mexican lime (C. aurantiifolia (Christm.) Swingle) and black rot of fruit of several Citrus spp. ${ }^{10}$ Endophyte Alternaria spp. are common saprophytes on all aboveground tissues of citrus trees.
Phylogenetic studies on citrus-associated species of Alternaria using mitochondrial large subunit (mtLSU) and $\beta$-tubulin sequence data formed a well-supported monophyletic lineage including isolates that cause ABS of tangerines and leaf spot of rough lemon, as well as saprophytic isolates associated with citrus and other plants ${ }^{11}$. ABS and leaf spot pathotypes produce host-selective ACT and ACR toxins, respectively. These two pathotypes have clearly distinct host ranges as they produce distinct host-selective toxins ${ }^{12,13}$. ABS and other leaf spot pathogens cause necrotic lesions on leaves and twigs; and lesions may expand rapidly due to production of a hostspecific toxin by the pathogens, often resulting in leaf drop and twig dieback. On fruit, lesions vary from small dark necrotic spots to large sunken pockmarks, thereby reducing the value of fruit for the fresh market $^{12}$. Sequencing of many regions of DNA is used in classification, identification, and biotechnology of fungi. Internal Transcribed Spacer (ITS) regions of ribosomal DNA show higher degrees of variation than other genetic regions of rDNA. This genomic region is typically used in fungal systematics and identifica- 
tion of genetic differences at species and subspecies levels ${ }^{14}$. Much research has focused on identification of genetic differences among citrus-associated Alternaria spp. ${ }^{11,15-17}$ but little is known about genetic differences among Alternaria isolates from individual citrus species. The objective of this study was to clarify that Alternaria isolates collected from tangerine cultivars had genetic differences (based on ITS sequences). A secondary objective was to identify pathogenic Alternaria spp. isolates collected from leaf spots of tangerine cultivars of orchards in Jahrom region, Iran.

\section{MATERIAL AND METHODS}

\section{Sample collection and monoconidial isolates}

In autumn 2011, tangerine leaf samples affected by brown spot were collected from the Jahrom Citrus Research Station and citrus orchards of Jahrom region, Iran. There were 56 samples collected from 13 tangerine cultivars: Firchaid, Minneola tangelo, Oncho, Dansy, Orlando tangelo, Clementine, Fortune, Peache, Oseola, local (Mahalli), Kinnow, Lee, and Ponkan. Samples were placed in plastic bags and rapidly transferred to the laboratory. Collected leaves were washed with tap water. A $5-\mathrm{mm}^{2}$ section was removed from the leading edge of the lesion and sterilized with $0.1 \%$ $\mathrm{NaOCl}$ for 30-60 s. Leaf sections were soaked three times in $40 \mathrm{ml}$ of sterile water, dried with a paper towel, and plated onto Petri dishes containing acidified potato dextrose agar (PDA) and incubated for 7 days at $22{ }^{\circ} \mathrm{C}$. After growth of fungi, a small piece of this culture containing conidia transferred to a few drops of sterile distilled water on sterile microscope slide and well stirred. A drop of spore suspension was streaked across the $2 \%$ water agar plate using sterile loop. The plates were incubated for $24 \mathrm{~h}$ at $25^{\circ} \mathrm{C}$. A monoconidial culture was produced by transferring one germinating conidia from $2 \%$ water agar (WA) to PDA.

\section{Pathogenicity test}

Disease-free leaves were collected from each tangerine cultivar. Tests were conducted on unwounded and wounded leaves (by scalpel) and surface disinfected by $70 \%$ alcohol, maintained on $2 \%$ WA and inoculated with 5.0-mm plugs of 7-day old monoconidial cultures of the fungal isolates. The inoculum was placed in the middle of each leaf. Leaves for control were sham inoculated with a plug of sterile PDA. Inoculated leaves were then maintained in an incubator for 7 days at $25^{\circ} \mathrm{C}$. The pathogenicity test was repeated twice. At the end of the experiment, the pathogen was re- isolated from the infected leaves to complete Koch's postulates. Pathogenic isolates were identified using morphological characteristics and DNA sequence analysis of the ITS1 region.

\section{Morphological characterization}

For all isolates, morphological characteristics of the colony and sporulation apparatus were determined from single-spore colonies. Cultures were examined for colour, margin, and texture of colonies. Sporulation habit of isolates was investigated on PDA Petri dishes. Dishes were inoculated with single-spore colonies and incubated in a lit incubator for 7 days at $22{ }^{\circ} \mathrm{C}$. For consistent sporulation, the dishes were kept $31 \mathrm{~cm}$ below cool white fluorescent bulbs and illuminated with 10/14 h periods of light/dark. During light periods, the illumination intensity at the surface of the Petri dishes was approximately $4000 \mathrm{~lx}$. After incubation, cultures were examined at $\times 40$ to $\times 100$ magnifications with a dissecting microscope and substage illumination to determine the characteristics of the sporulation apparatus, including length of conidial chains, presence of elongated secondary conidiophores, and the manner of any branching of the conidial chains.

A completely randomized design with three replicates was used for growth of isolates on PDA medium. A small disc of monoconidial PDA cultures of the fungus were placed in the centre of each Petri plate. Every 2 days, fungal growth was measured from the point of inoculation to the outer edge of the infection zone across a plate. The measurements were taken at two longitudinal positions on each of the plates to the nearest $\mathrm{mm}$ for 8 days. Means of treatments were compared by Duncan's multiple range test at $5 \%$ significance level, using SAS software.

\section{Molecular analysis}

Genomic DNA was extracted from pure cultures using the CTAB method. Eight isolates were selected and examined for molecular characteristics. PCR amplification was performed using a thermocycler. Each $25 \mu \mathrm{l} \mathrm{PCR}$ reaction mixture consisted of $18 \mu \mathrm{l}$ of sterile $\mathrm{ddH}_{2} \mathrm{O}, 2.5 \mu \mathrm{l}$ of $10 \times$ PCR buffer (Promega), $1.5 \mu \mathrm{l}$ of $\mathrm{MgCl}_{2}(25 \mathrm{mM}), 0.75 \mu \mathrm{l}$ of dNTP $(10 \mathrm{mM}$ total, $2.5 \mathrm{mM}$ each $), 0.75 \mu \mathrm{l}$ of each primer $(20 \mathrm{ng} / \mu \mathrm{l}), 0.1 \mu \mathrm{l}$ of $\mathrm{Taq}$ polymerase (Promega) $(5 \mathrm{U} / \mu \mathrm{l})$, and $0.65 \mu \mathrm{l}$ of template DNA $(80 \mathrm{ng} / \mu \mathrm{l})$. PCR cycles consisted of an initial denaturation step at $94^{\circ} \mathrm{C}$ for 5 min followed by 30 cycles of $35 \mathrm{~s}$ at $94{ }^{\circ} \mathrm{C}$ (denaturation), $55 \mathrm{~s}$ at $55^{\circ} \mathrm{C}$ (annealing), and 1 min at $72{ }^{\circ} \mathrm{C}$ (extension). A final extension cycle at $72{ }^{\circ} \mathrm{C}$ for $15 \mathrm{~min}$ was followed by a $4{ }^{\circ} \mathrm{C}$ soak period. The PCR products were 


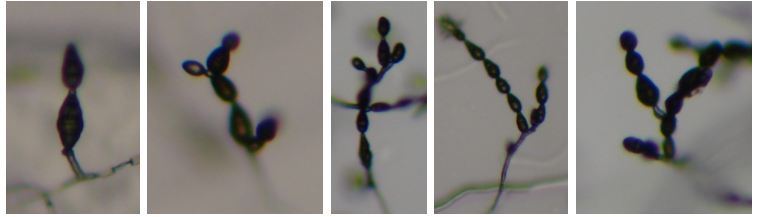

Fig. 1 Conidial development of A. alternata.

visualized with UV light after $1 \%$ agarose-gel electrophoresis in $1 \times$ TBE stained with ethidium bromide. ITS universal primer pair ITS1-F/ITS2 was used to amplify the ITS1 region ${ }^{18}$. PCR products amplified from the primer pair ITS1-F/ITS2 were sequenced (Macrogen Inc., Korea) and BLAST searched in the GenBank database. Sequences of A. alternata isolates were deposited in GenBank (accession no. KJ021885KJ021892). The ITS sequences were aligned using MEGA4 package. Phylogenetic unrooted trees were constructed using distance methods. For distance analysis, the neighbour-joining method was performed. For each analysis, 1000 bootstrap replicates were performed to assess the statistical support for each tree.

\section{RESULTS}

\section{Identification of species}

Both morphological characterization and the ITS region nucleotide sequences were used to identify pathogen species. For all isolates, the morphological characteristics of the colony and sporulation apparatus were compared with the characters described by Simmons (2007) for Alternaria spp. ${ }^{19}$ The morphological characteristics of all isolates were most similar to those of A. alternata. There was however a significant variation in colony colour and growth rate among the isolates. The sequence analysis confirmed the morphological identification. Sequence analysis of the ITS1 regions of isolates revealed $99-100 \%$ similarity to ITS1 region sequences of A. alternata and A. tenuisima in GenBank.

\section{Morphological characterization}

Fungal colonies were olive green to sooty-black in colour and showed a minutely-densely turfy surface. During the initial colony growth, a white margin of mycelia was observed that progressively changed to olive green, and then to grey-black. Single suberect conidiophores arose on aerial mycelia and produced clusters of small conidia in branched chains (Fig. 1). Conidia were yellowish to golden brown with longitudinal and transverse septa and a short beak.

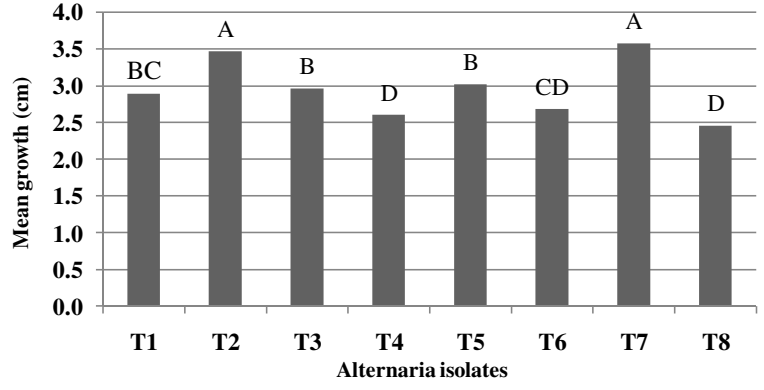

Fig. 2 Mean of 6 days of growth of A. alternata isolates on PDA. T1, Clementine; T2, Ponkan; T3, Peache; T4, Fortune; T5, Lee; T6, Oseola; T7, local; and T8, Kinnow. A, B, C, and D are Duncan's grouping.
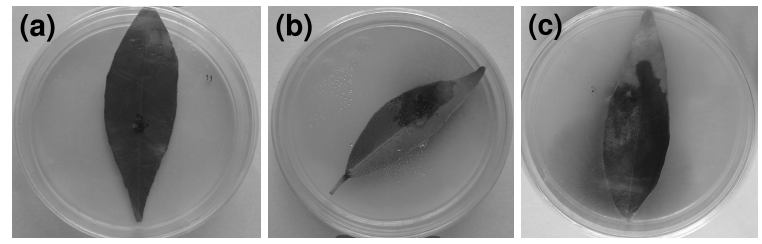

Fig. 3 Disease development on inoculated leaves; (a) Inoculation of healthy leaf, (b) appearance of disease symptom on inoculated leaf, (c) developed symptoms in leaf.

The mean colony growth of isolates on PDA showed significant differences. Ponkan and local showed maximum growth, and Fortune and Kinnow isolates the minimum growth (Fig. 2).

\section{Pathogenicity tests}

Pathogenicity tests on wounded and unwounded leaves resulted in significant lesion development for all isolates tested. At 2-3 and 7-10 days after inoculation, there was initial development of small dark lesions on the upper side of wounded and unwounded leaves, respectively, indicating infection establishment. Lesions expanded to cover the whole leaf in about 7 and 21 days for wounded and unwounded leaves, respectively. However, leaves inoculated with sterile PDA plugs remained disease free (Fig. 3). There were some differences in the lesion expansion among tested isolates. These observations indicate that all isolates were pathogenic on tangerine leaves.

\section{Phylogenetic analysis}

Amplification of ITS1 region using primers ITS1F/ITS2 produced 360-bp amplicons that were edited before alignment. No length polymorphism was observed among isolates (Fig. 4).

Maximum likelihood analysis of ITS1 sequence data revealed three main clades (Fig. 5). The phylo- 


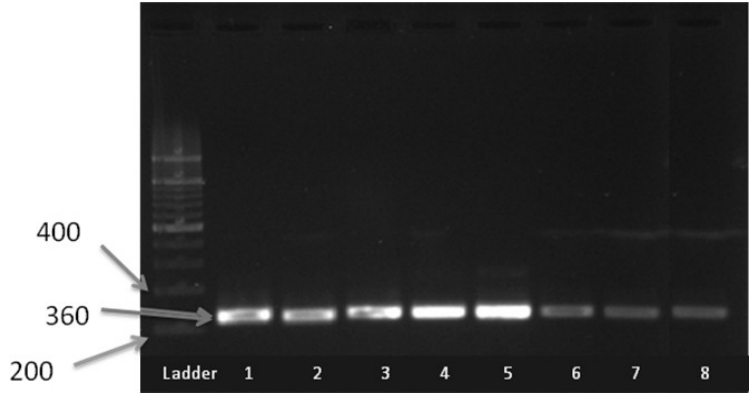

Fig. 4 DNA patterns amplified from two primer pairs in Alternaria alternata. 1: Clementine, 2: Ponkan, 3: Peache, 4: Fortune, 5: Lee, 6: Oseola, 7: local, 8: Kinnow.

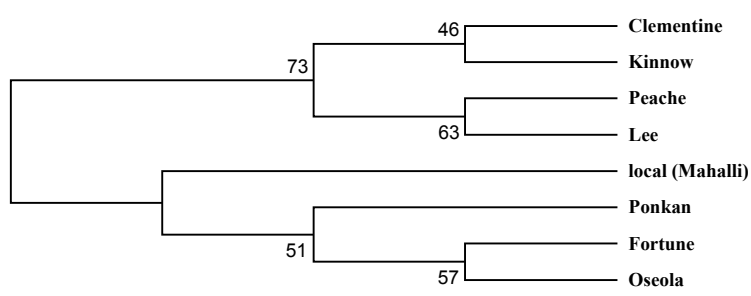

Fig. 5 Unrooted phylogeny estimated among A. alternata isolates sampled from tangerine cultivars. Phylogeny was estimated using maximum likelihood, and numbers at the major nodes indicate the percentage occurrence of the clade to the right of the node in 1000 bootstrapped datasets.

genies estimated in this study were unrooted. Clade 1 consisted of two subclades including Clementine, Kinnow, Peache, and Lee. Clade 2 contained only one isolate from Mahalli. Three isolates, including Ponkan, Fortune and Osceola were found in clade 3.

\section{DISCUSSION}

Of several A. spp. causing disease on citrus trees, A. alternata is the most prominent ${ }^{20-24}$. Additionally, A. alternata has been reported from many citrus species in northern $\operatorname{Iran}^{25}$. In this study, A. alternata was identified as the cause of ABS of tangerine cultivars in southern Iran for the first time.

Non-pathogenic isolates of A. alternata collected from Minneola tangelo have been reported in Florida ${ }^{16}$, but the vast majority of the isolates were pathogenic to that host. The present study indicated that all A. alternata isolates were pathogenic on the host of origin and non-pathogenic isolates were not observed. The different development of symptoms on tangerine leaves confirmed that some isolates were more virulent than others - also, isolates differed in growth on PDA media. Although disease progress on detached leave was not measured, Ponkan and local isolates showed the highest growth under controlled conditions on cultural media, and these two isolates may be the most virulent. Previous reports indicated that the more virulent isolates of A. alternata have more copies of genes controlling toxin biosynthesis and produce more ACT-toxin than other isolates ${ }^{11}$. Ponkan and local isolates may be more virulent due to greater production of toxins. More study is required to confirm this.

There were significant differences in morphology and growth rate of isolates, suggesting that the Alternaria population on tangerine in Jahrom region citrus groves was not typical and was quite variable. The ITS1 sequencing confirmed the results as the local (Mahalli) isolate showed high growth rate on PDA media and in the phylogenetic analysis was grouped in a single clade. These results may explain why morphological variations and ITS1 sequences were correlated with each other. The differences in ITS1 sequences however were small. Peever et $\mathrm{al}^{26}$ sequenced endopolygalacturonase gene (endoPG) and two anonymous regions of the genomes (OPA1-3 and OPA2-1) of A. alternata isolates recovered from brown spot lesions on Minneola tangelo and the other citrus and non-citrus hosts ${ }^{26}$. They reported that isolates recovered from ABS lesions on Minneola tangelo were distributed in two clades ${ }^{26}$, indicating genetic variations among tangerine isolates of $\mathrm{A}$. alternata.

The ITS1 sequences of $A$. alternata were very similar to $A$. tenuissima sequences (99-100\% similarity). Thus these two species cannot be distinguished by ITS 1 sequences. Many researchers have reported that differentiation of the small-spored Alternaria spp. is difficult due to lack of variation in nuclear ribosomal ITS and $\beta$-tubulin sequences, two genomic regions typically used in fungal systematic ${ }^{17,27}$.

The A. alternata population of tangerine in Jahrom region orchards showed high morphological and genetic diversity, which may provide information on genetic differences among tangerine isolates from different cultivars. Identification of such diversities has a direct impact on epidemiological studies and disease management of ABS of tangerine. Different isolates showed different growth rates and some differences in ITS1 sequences. All of these factors are important in the development of disease forecasting models, which are critical in optimizing effective and economical chemical control programs. From another point of view, using resistant cultivars to control this disease in citrus groves completely depends on our knowledge of genetic differences among pathogenic agents. The most successful management of ABS 
of tangerine will be achieved only after a definitive assessment of the genetic and pathogenic diversity of A. alternata isolates in citrus orchards, and the potential for these distinct isolates to cause disease.

Acknowledgements: The authors are grateful to Jalal Novrooznejad (plant diseases laboratory technician) for valuable suggestions and discussions. This work was partially supported by research assistant of Jahrom Branch of Islamic Azad University.

\section{REFERENCES}

1. Cobb NA (1903) Letters on the diseases of plants: Alternaria of the citrus tribe. Agr Gaz New S Wales 14, 955-86.

2. Peever TL, Ibañez A, Akimitsu K, Timmer LW (2002) Worldwide phylogeography of the citrus brown spot pathogen, Alternaria alternata. Phytopathology 92, 794-802.

3. Swart SH, Wingfield MJ, Swart WJ, Schutte GC (1998) Chemical control of Alternaria brown spot on Minneola tangelo in South Africa. Ann Appl Biol 133, 17-30.

4. Canihos Y, Erkilic A, Timmer LW (1997) First report of Alternaria brown spot of Minneola tangelo in Turkey. Plant Dis 81, 1214.

5. Vicent A, Armengol J, Sales R, García-Jiménez J, Alfaro-Lassala F (2000) First report of Alternaria brown spot of citrus in Spain. Plant Dis 84, 1044.

6. Bella P, La Rosa R, Catara V, Polizzi G (2001) Extreme susceptibility of Primosole mandarin to Alternaria fruit rot in Italy. Plant Dis 85, 1291.

7. Wang XF, Li ZA, Tang KZ, Zhou CY, Yi L (2010) First report of Alternaria brown spot of citrus caused by Alternaria alternata in Yunnan province. Plant Dis 94, 375.

8. Peres NAR, Agostini JP, Timmer LW (2003) Outbreaks of Alternaria brown spot of citrus in Brazil and Argentina. Plant Dis 87, 750.

9. Golmohammadi M, Andrew M, Peever TL, Peres NA, Timmer LW (2006) Brown spot of tangerine hybrid cultivars Minneola, Page and Fortune caused by Alternaria alternata in Iran. Plant Pathol 55, 578.

10. Timmer LW, Peever TL, Solel Z, Akimitsu K (2003) Alternaria diseases of citrus: novel pathosystems. Phytopathol Mediterr 42, 99-112.

11. Peever TL, Su G, Carpenter-Boggs L, Timmer LW (2004) Molecular systematics of citrus-associated $\mathrm{Al}$ ternaria species. Mycologia 96, 119-34.

12. Akimitsu K, Kohmoto K, Otani H, Nishimura S (1989) Host-specific effects of toxin from the rough lemon pathotype of Alternaria alternata on mitochondria. Plant Physiol 89, 925-31.

13. Yago JI, Lin CH, Chung KR (2013) The SLT2 mitogenactivated protein kinase-mediated signalling pathway governs conidiation, morphogenesis, fungal virulence and production of toxin and melanin in the tangerine pathotype of Alternaria alternata. Mol Plant Pathol 12, 653-65.

14. Peay KG, Kennedy PG, Bruns TD (2008) Fungal community ecology: a hybrid beast with a molecular master. BioScience 58, 799-810.

15. Kusaba M, Tsuge T (1995) Phologeny of Alternaria fungi known to produce host-specific toxins on the basis of variation in internal transcribed spacers of ribosomal DNA. Curr Genet 28, 491-8.

16. Peever TL, Canihos Y, Olsen L, Ibañez A, Liu YC, Timmer LW (1999) Population genetic structure and host specificity of Alternaria spp. causing brown spot of Minneola tangelo and rough lemon in Florida. Phytopathology 89, 851-60.

17. Pryor BM, Michailides TJ (2002) Morphological, pathogenic, and molecular characterization of $\mathrm{Al}$ ternaria isolates associated with Alternaria late blight of pistachio. Phytopathology 92, 406-16.

18. White TJ, Bruns T, Lee S, Taylor J (1990) Amplification and direct sequencing of fungal ribosomal RNA genes for phylogenetics. In: Innis MA, Gelfand DH, Sninsky JJ, White TJ (eds) PCR Protocols: A Guide to Methods and Applications, Academic Press, San Diego, CA, pp 315-22.

19. Simmons EG (2007) Alternaria: An Identification Manual. CBS Fungal Biodiversity Centre, Utrecht, The Netherlands.

20. Kohmoto K, Akimitsu K, Otani H (1991) Correlation of resistance and susceptibility of citrus to Alternaria alternata with sensitivity to host-specific toxins. Phytopathology 81, 719-22.

21. Kohmoto K, Scheffer RP, Whiteside JO (1979) Hostselective toxins from Alternaria citri. Phytopathology 69, 667-71.

22. Palm ME, Civerolo EL (1994) Isolation, pathogenicity, and partial host range of Alternaria limicola, causal agent of mancha foliar de los citricos in Mexico. Plant Dis 78, 879-83.

23. Solel Z (1991) Alternaria brown spot on Minneola tangelos in Israel. Plant Pathol 40, 145-7.

24. Timmer LW, Solel Z, Orozco-Santos M (2000) Alternaria brown spot of mandarins. In: Timmer LW, Garnsey SM, Graham JH eds. Compendium of Citrus Diseases, 2nd edn, APS Press, St. Paul, MN, pp 19-21.

25. Rouhibakhsh A, Ershad D (1997) An investigation on mycoflora of citrus necrotic spots in Western part of Mazandaran. Iran J Plant Pathol 33, 94-110.

26. Peever TL, Carpenter-Boggs L, Timmer LW, Carris LM, Bhatia A (2005) Citrus black rot is caused by phylogenetically distinct lineages of Alternaria alternata. Phytopathology 95, 512-8.

27. Pryor BM, Gilbertson RL (2000) Molecular phylogenetic relationships amongst Alternaria species and related fungi based upon analysis of nuclear ITS and mtSSU rDNA sequences. Mycol Res 104, 1312-21. 